\title{
Penerapan Algoritma PROMETHEE Pada Seleksi Proposal Program Kreativitas Mahasiswa (PKM) pada STIKOM Tunas Bangsa Pematangsiantar
}

\author{
Riyani Wulan Sari' ${ }^{1}$, Agus Perdana Windarto ${ }^{2}$, Eka Irawan ${ }^{3}$ \\ Sistem Informasi STIKOM Tunas Bangsa Pematangsiantar ${ }^{123}$ \\ Email: riyaniwulansari24@gmail.com ${ }^{1}$, agusperdanawindarto@amiktunasbangsa.ac.id ${ }^{2}$
}

\begin{abstract}
The Student Creativity Program (PKM) is a prestigious event for students where funding is carried out by DIKTI for proposals that pass the selection. The intense competition between students throughout Indonesia requires institutions to select proposals that are feasible to compete at the National level. This study discusses the Application of PROMETHEE Algorithm to Selection of Student Creativity Program (PKM) File Proposals on STIKOM Tunas Bangsa Pematangsiantar. The data used in this study were obtained directly from the chairman of the Institute for Research and Community Service (LLPM) STIKOM Tunas Bangsa by interview and observation. The criteria used as a requirement in the selection of PKM proposal file selection are title (C1), abstract (C2), introduction (C3), goal (C4), method (C5), results and discussion (C6), conclusion (C7), and bibliography (C8). This research is expected to be a recommendation to STIKOM Tunas Bangsa, especially LPPM in selecting PKM proposal files, considering that this is a prestigious event for students throughout Indonesia.
\end{abstract}

Keywords: Decision Support Systems, Student Creativity Program, PROMETHEE

Abstrak - Program Kreativitas Mahasiswa (PKM) merupakan ajang bergengsi bagi mahasiswa dimana pendanaannya dilakukan oleh DIKTI bagi proposal yang lulus seleksi. Persaingan ketat antara mahasiswa diseluruh Indonesia mengharuskan lembaga menyeleksi proposal yang layak untuk diperlombakan ditingkat Nasional. Penelitian ini membahas tentang Penerapan Algoritma PROMETHEE pada Seleksi Berkas Proposal Program Kreativitras Mahasiswa (PKM) pada STIKOM Tunas Bangsa Pematangsiantar. Data yang digunakan dalam penelitian ini didapatkan langsung dari ketua Lembaga Penelitian dan Pengabdian kepada Masyarakat (LLPM) STIKOM Tunas Bangsa dengan cara wawancara dan observasi. Adapun kriteria yang dijadikan syarat dalam pemilihan seleksi berkas proposal PKM ini yaitu judul (C1), abstrak (C2), pendahuluan (C3), tujuan (C4), algoritma (C5), hasil dan pembahasan (C6), kesimpulan (C7), dan daftar pustaka (C8). Penelitian ini diharapkan dapat menjadi rekomendasi kepada STIKOM Tunas Bangsa khususnya LPPM dalam melakukan seleksi berkas proposal PKM mengingat hal ini merupakan ajang bergengsi bagi mahasiswa diseluruh Indonesia.

Kata Kunci: Sistem Pendukung Keputusan, Program Kreatifitas Mahasiswa, PROMETHEE

\section{PENDAHULUAN}

STIKOM Tunas Bangsa merupakan salah satu Perguruan Tinggi Swasta di Sumatera Utara yang beralamatkan di Jalan Jend. Sudirman Blok A. No. 1,2 dan 3 Pematangsiantar. STIKOM Tunas Bangsa merupakan sekolah tinggi ilmu komputer untuk program studi Sistem Informasi dan Teknik Informatika yang telah mendapat ijin sesuai dengan keluarnya "IJIN MENDIKBUD R.I N0.408/E/0/2014 7 TANGGAL 11 SEPTEMBER 2014" dari pemerintah. Dalam menjalankan aktivitas, 
STIKOM Tunas Bangsa memiliki beberapa lembaga diantaranya Lembaga Penelitian dan Pengabdian kepada Masyarakat (LPPM) STIKOM Tunas Bangsa. Salah satu tugas lembaga tersebut yaitu menangani kegiatan penelitian dan pengabdian yang merupakan wadah bagi para dosen dan mahasiswa untuk menerapkan dan mengembangkan keilmuan dan pengetahuan yang dimiliki. Salah satu kegiatan LPPM STIKOM Tunas Bangsa yaitu menangani proposal kemahasiswaan yang akan diperlombakan pada tingkat Nasional. Proses ini berawal dari pemilihan proposal yang akan diseleksi oleh lembaga tersebut sebelum nantinya diseleksi secara Nasional.

Proposal kemahasiswaan tersebut diberi nama Program Kreativitas Mahasiswa (PKM) yang merupakan ajang bergengsi bagi mahasiswa dimana pendanaannya dilakukan oleh DIKTI bagi proposal PKM yang lulus seleksi. Persaingan ketat antara mahasiswa diseluruh Indonesia mengharuskan lembaga menyeleksi proposal yang layak untuk di perlombakan di tingkat Nasional. Program Kreatifitas Mahasiswa (PKM) merupakan salah satu upaya yang dilakukan oleh Direktorat Riset dan Pengabdian masyarakat (semula Direktorat Penelitian dan Pengabdian kepada Masyarakat Ditjen Dikti), Direktorat Jenderal Penguatan Riset dan Pengembangan, Kementerian Ristek Dikti untuk meningkatkan mutu peserta didik (mahasiswa) di Perguruan Tinggi agar kelak dapat menjadi anggota masyarakat yang memiliki kemampuan akademis atau profesional yang dapat menerapkan, mengembangkan dan meyebarluaskan ilmu pengetahuan, teknologi atau kesenian serta memperkaya budaya nasional.

\section{METODOLOGI PENELITIAN}

\subsection{Sistem Pendukung Keputusan}

Sistem Pendukung Keputusan (SPK) adalah salah satu cara mengorganisir informasi yang dimaksudkan untuk digunakan dalam membuat keputusan. Ada yang mendefinisikan bahwa system pendukung keputusan merupakan suatu pendekatan untuk mendukung pengambilan keputusan. Sistem pendukung keputusan menggunakan data, memberikan antarmuka pengguna yang mudah dan dapat menggabungkan pemikiran pengambil keputusan[1]. Sistem pendukung keputusan merupakan sebuah sistem yan memberikan kemampuan komunikasi untuk masalah semi terstruktur[2].

\subsection{Algoritma PROMETHEE}

PROMETHEE merupakan salah satu dari algoritma Multi Criteria Decision Making (MCDM) yang berarti melakukan penentuan atau pengurutan dalam suatu analisis multikriteria, algoritma ini dikenal karena konsepnya yang efisien dan simple, selain itu untuk menyelesaikan masalah yang berhubungan dengan multikriteria, algoritma ini juga sangat mudah untuk diterapkan daripada algoritma lainnya[3]. Adapun langkah-langkah yang digunakan dalam melakukan perhitungan dengan aloritma PROMETHEE yaitu[4] :

a. Pengumpulan data kriteria serta alternatif penghematan

b. Penentuan preferensi (tipe, kaidah dan parameter dari fungsi preferensi)

c. Perhitungan nilai preferensi dan indeks preferensi Melakukan perhitungan dengan mengurangkan alternatif yang satu dengan yang lainnya. 
Perhitungan indeks preferensi $=\pi(a, b)=\frac{1}{k} \sum_{j=1}^{k} w_{j} \cdot p_{j}(a, b)$

$\pi(a, b)=$ Nilai indeks preferensi

$\mathrm{K} \quad=$ Jumlah kriteria

$p_{j}(a, b)=$ Nilai preferensi a terhadap $\mathrm{b}$

Perhitungan Leaving Flow, Entering Flow, dan Net Flow

1. Leaving Flow $=\varphi^{+}(a)=\frac{1}{n-1} \sum_{x \in a} \varphi(a, x)$

2. Entering Flow $=\varphi^{-}(a)=\frac{1}{n-1} \sum_{x \in a} \varphi(a, x)$

3. Net Flow $=\varphi(a)=\varphi^{+}(a)-\varphi^{-}(a)$

\subsection{Seleksi Berkas}

Seleksi berkas adalah suatu proses untuk memilih berkas yang sesuai dengan persyaratan atau standar yang sudah ditetapkan[5]. Penelitian ini dilakukan di STIKOM Tunas Bangsa Pematangsiantar dengan menggunakan algoritma PROMETHEE dimana algoritma ini merupakan algoritma yang cukup efektif dalam melakukan pengambilan keputusan dan diproses menggunakan aplikasi berbasis Web untuk melakukan seleksi berkas proposal Program Kreativitas Mahasiswa (PKM). Data yang digunakan dalam penelitian ini didapatkan langsung dari ketua Lembaga Penelitian dan Pengabdian kepada Masyarakat (LLPM) STIKOM Tunas Bangsa dengan cara wawancara dan observasi dengan total sampel data yang digunakan adalah 6 alternatif dan 8 kriteria. Bentuk diagram alir (flowchart) dapat menggambarkan dengan jelas mengenai proses tahapan maupun langkah dalam penerapan menggunakan algoritma PROMETHEE. Flowchart adalah representasi secara simbolik dari suatu algoritma atau prosedur untuk menyelesaikan suatu masalah, dengan menggunakan flowchart akan memudahkan pengguna melakukan pengecekan bagian-bagian yang terlupakan dalam analisis masalah, disamping itu flowchart juga berguna sebagai fasilitas untuk berkomunikasi antara pemrogram yang bekerja dalam tim suatu proyek[6]. Flowchart dapat dideskripsikan pada Gambar 1. berikut:

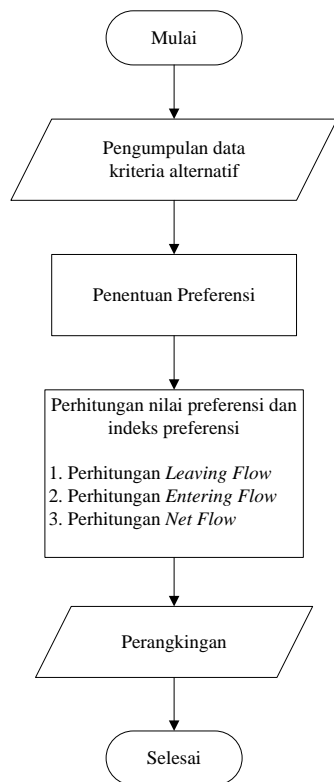

Gambar 1. Diagram Alir Aloritma Penelitian 
Sesuai pada gambar diatas dapat disimpulkan algoritma penelitian yang digunakan adalah sebagai berikut:

1) Pengumpulan data kriteria alternative

Pada tahap ini data yang sudah diberikan penilaian oleh riviewer dikumpulkan sesuai dengan kriteria dan alternatif yang telah ditentukan.

2) Penentuan Preferensi

Pada tahap ini dilakukan perbandingan antara satu alternatif dengan alternatif lainnya, dengan cara mengurangkan nilai alternatif pertama dengan alternatif kedua, kemudian dihitung nilai preferensinya sesuai dengan tipe preferensi yang digunakan.

3) Perhitungan nilai preferensi dan indeks preferensi

Pada tahap ini dilakukan perhitungan yaitu perhitungan Leaving Flow, Entering Flow, dan Net Flow.

a) Leaving Flow, digunakan untuk menentukan urutan prioritas pada proses PROMETHEE yang menggunakan urutan parsial.

b) Entering Flow, selain Leaving Flow untuk menentukan urutan prioritas pada proses PROMETHEE yang menggunakan urutan parsial juga digunakan perhitungan Entering Flow.

c) Net Flow, digunakan untuk menghasilkan keputusan akhir penentuan urutan dalam menyelesaikan urutan lengkap.

4) Perangkingan

Perangkingan dilakukan dengan mengurutkan alternatif berdasarkan nilai tertinggi sampai dengan nilai terendah. Nilai yang tertinggi mendapatkan rangking satu dan seterusnya sampai alternatif yang sudah ditentukan.

\section{HASIL DAN PEMBAHASAN}

\subsection{Proses Data Masukan}

Untuk menentukan alternatif dan kriteria peneliti telah melakukan wawancara langsung kepada narasumber. Dalam penelitian ini ada lima belas alternatif dan delapan kriteria yaitu :

Tabel 1. Data Kriteria dan Bobot

\begin{tabular}{|l|c|}
\hline \multicolumn{1}{|c|}{ Kriteria } & Bobot \\
\hline Judul (C1) & 5 \\
\hline Abstrak (C2) & 10 \\
\hline Pendahuluan (C3) & 10 \\
\hline Tujuan (C4) & 5 \\
\hline Algoritma (C5) & 25 \\
\hline Hasil dan Pembahasan (C6) & 30 \\
\hline Kesimpulan (C7) & 10 \\
\hline Daftar Pustaka (C8) & 5 \\
\hline
\end{tabular}

Tabel 2. Tabel Kepentingan

\begin{tabular}{|c|c|}
\hline Skor & Keterangan \\
\hline 1 & Buruk \\
\hline 2 & Sangat kurang \\
\hline
\end{tabular}




\begin{tabular}{|c|c|}
\hline Skor & Keterangan \\
\hline 3 & Kurang \\
\hline 5 & Cukup \\
\hline 6 & Baik \\
\hline 7 & Sangat baik \\
\hline
\end{tabular}

Tabel 3. Data Alternatif Penilaian dari Reviewer yang telah diolah

\begin{tabular}{|c|c|c|c|c|c|c|c|c|}
\hline \multirow{2}{*}{ Alternatif } & \multicolumn{9}{|c|}{ Kriteria } \\
\cline { 2 - 9 } & Judul & Abstrak & Pendahuluan & Tujuan & Algoritma & $\begin{array}{c}\text { Hasil dan } \\
\text { Pembahasan }\end{array}$ & Kesimpulan & $\begin{array}{c}\text { Daftar } \\
\text { Pustaka }\end{array}$ \\
\hline A1 & 30 & 50 & 60 & 15 & 75 & 180 & 60 & 35 \\
\hline A2 & 25 & 30 & 50 & 30 & 125 & 210 & 50 & 25 \\
\hline A3 & 15 & 50 & 50 & 25 & 175 & 180 & 30 & 15 \\
\hline A4 & 30 & 60 & 60 & 30 & 150 & 150 & 30 & 10 \\
\hline A5 & 35 & 70 & 30 & 35 & 75 & 90 & 20 & 25 \\
\hline A6 & 25 & 50 & 70 & 30 & 75 & 150 & 50 & 15 \\
\hline A7 & 15 & 60 & 50 & 25 & 125 & 180 & 20 & 25 \\
\hline A8 & 30 & 30 & 60 & 25 & 150 & 150 & 30 & 30 \\
\hline A9 & 15 & 30 & 70 & 15 & 175 & 90 & 30 & 35 \\
\hline A10 & 35 & 50 & 30 & 25 & 150 & 90 & 60 & 25 \\
\hline A11 & 30 & 30 & 50 & 35 & 125 & 60 & 50 & 35 \\
\hline A12 & 25 & 30 & 50 & 10 & 50 & 90 & 60 & 25 \\
\hline A13 & 15 & 30 & 20 & 15 & 75 & 150 & 70 & 30 \\
\hline A14 & 10 & 50 & 30 & 30 & 50 & 180 & 60 & 15 \\
\hline A15 & 25 & 60 & 50 & 10 & 75 & 210 & 50 & 15 \\
\hline
\end{tabular}

\subsection{Proses Algoritma PROMETHEE}

a. Menentukan tipe preferensi untuk tiap-tiap kriteria secara tepat.

Setelah ditentukan tipe fungsi prefrensi yang digunakan. Selanjutnya mencari nilai prefrensi dengan membandingkan setiap alternatif. Nilai prefrensi diperoleh berdasarkan tipe prefrensi yang digunakan.

Mhs 1 , Mhs $2=30-30=0=0$

Mhs 2, Mhs $1=30-30=0=0$

Mhs 1 , Mhs $3=30-25=5=1$

Mhs 3, Mhs $1=25-30=(-5)=0$

Mhs 3, Mhs $1=25-30=(-5)=0$

Mhs 4 , Mhs $1=30-30=0=0$

Mhs 1 , Mhs $5=30-35=(-5)=0$

Mhs 5, Mhs $1=35-30=5=1$

Mhs 1 , Mhs $6=30-30=0=0$

Mhs 6, Mhs $1=30-30=0=0$

Mhs 2, Mhs $3=30-25=5=1$

Mhs 3, Mhs $2=25-30=(-5)=0$

Mhs 2, Mhs $4=30-30=0=0$

Mhs 4, Mhs $2=30-30=0=0$

Mhs 2, Mhs $5=30-35=(-5)=0$
Mhs 5 , Mhs $2=35-30=5=1$

Mhs 2, Mhs $6=30-30=0=0$

Mhs 6, Mhs $2=30-30=0=0$

Mhs 3, Mhs $4=25-30=(-5)=0$

Mhs 4 , Mhs $3=30-25=5=1$

Mhs 3, Mhs $5=25-35=(-10)=0$

Mhs 5, Mhs $3=35-25=10=1$

Mhs 3, Mhs $6=25-30=(-5)=0$

Mhs 6, Mhs $3=30-25=5=1$

Mhs 4 , Mhs $5=30-35=(-5)=0$

Mhs 5, Mhs $4=35-30=5=1$

Mhs 4 , Mhs $6=30-30=0=0$

Mhs 6, Mhs $4=30-30=0=0$

Mhs 5 , Mhs $6=35-30=5=1$

Mhs 6 , Mhs $5=30-35=(-5)=0$ 
Dari beberapa perhitungan diatas, dengan membandingkan setiap alternatif maka nilai keseluruhan preferensi dapat dilihat seperti yang ditunjukkan pada tabel 4. berikut :

Tabel 4. Nilai Preferensi

\begin{tabular}{|c|c|c|c|c|c|c|c|c|c|}
\hline No & Alternatif & \multicolumn{7}{|c|}{ Kriteria } \\
\hline 1 & Mhs 1, Mhs 2 & 0 & 0 & 0 & 1 & 1 & 0 & 0 & 1 \\
\hline 2 & Mhs 2, Mhs 1 & 0 & 0 & 1 & 0 & 0 & 0 & 0 & 0 \\
\hline 3 & Mhs 1, Mhs 3 & 1 & 1 & 1 & 1 & 1 & 0 & 1 & 1 \\
\hline 4 & Mhs 3, Mhs 1 & 0 & 0 & 0 & 0 & 0 & 0 & 0 & 0 \\
\hline 5 & Mhs 1, Mhs 4 & 0 & 0 & 0 & 0 & 0 & 0 & 1 & 1 \\
\hline 6 & Mhs 4, Mhs 1 & 0 & 0 & 0 & 0 & 0 & 0 & 0 & 0 \\
\hline 7 & Mhs 1, Mhs 5 & 0 & 0 & 0 & 0 & 1 & 1 & 1 & 1 \\
\hline 8 & Mhs 5, Mhs 1 & 1 & 0 & 1 & 0 & 0 & 0 & 0 & 0 \\
\hline 9 & Mhs 1, Mhs 6 & 0 & 0 & 0 & 1 & 0 & 0 & 0 & 1 \\
\hline 10 & Mhs 6, Mhs 1 & 0 & 0 & 0 & 0 & 0 & 0 & 0 & 0 \\
\hline 11 & Mhs 2, Mhs 3 & 1 & 1 & 1 & 1 & 1 & 0 & 1 & 1 \\
\hline 12 & Mhs 3, Mhs 2 & 0 & 0 & 0 & 0 & 0 & 0 & 0 & 0 \\
\hline 13 & Mhs 2, Mhs 4 & 0 & 0 & 1 & 0 & 0 & 0 & 1 & 0 \\
\hline 14 & Mhs 4, Mhs 2 & 0 & 0 & 0 & 1 & 1 & 0 & 0 & 0 \\
\hline 15 & Mhs 2, Mhs 5 & 0 & 0 & 0 & 0 & 0 & 1 & 0 & 0 \\
\hline 16 & Mhs 5, Mhs 2 & 1 & 0 & 0 & 1 & 0 & 0 & 1 & 0 \\
\hline 17 & Mhs 2, Mhs 6 & 0 & 0 & 1 & 0 & 0 & 0 & 0 & 0 \\
\hline 18 & Mhs 6, Mhs 2 & 0 & 0 & 0 & 0 & 1 & 0 & 0 & 0 \\
\hline 19 & Mhs 3, Mhs 4 & 0 & 0 & 0 & 0 & 0 & 0 & 0 & 0 \\
\hline 20 & Mhs 4, Mhs 3 & 1 & 1 & 1 & 1 & 1 & 0 & 0 & 1 \\
\hline 21 & Mhs 3, Mhs 5 & 0 & 0 & 0 & 0 & 0 & 1 & 0 & 0 \\
\hline 22 & Mhs 5, Mhs 3 & 1 & 1 & 1 & 1 & 1 & 0 & 0 & 1 \\
\hline 23 & Mhs 3, Mhs 6 & 0 & 0 & 0 & 0 & 0 & 0 & 0 & 0 \\
\hline 24 & Mhs 6, Mhs 3 & 1 & 1 & 1 & 0 & 1 & 0 & 1 & 1 \\
\hline 25 & Mhs 4, Mhs 5 & 0 & 0 & 0 & 0 & 1 & 1 & 0 & 0 \\
\hline 26 & Mhs 5, Mhs 4 & 1 & 0 & 1 & 0 & 0 & 0 & 0 & 0 \\
\hline 27 & Mhs 4, Mhs 6 & 0 & 0 & 0 & 1 & 0 & 0 & 0 & 0 \\
\hline 28 & Mhs 6, Mhs 4 & 0 & 0 & 0 & 0 & 0 & 0 & 1 & 0 \\
\hline 29 & Mhs 5, Mhs 6 & 1 & 0 & 1 & 1 & 0 & 0 & 0 & 0 \\
\hline 30 & Mhs 6, Mhs 5 & 0 & 0 & 0 & 0 & 1 & 1 & 1 & 0 \\
\hline
\end{tabular}

b. Menghitung indeks prefensi dari tiap-tiap kriteria.

Setelah diperoleh nilai prefrensi selanjutnya mencari nilai indeks prefrensi dengan menjumlah nilai prefrensi dari perbandingan alternatif lalu dibagi dengan jumlah kriteria.

Mhs 1 , Mhs $2=0+0+0+1+1+0+0+1$

$$
=0,375
$$

Mhs 2, Mhs $1=0+0+0+0+1+1+1+0$ $=0,125$

Mhs 1 , Mhs $3=1+1+1+1+1+0+1+1$ $=0,875$

Mhs 3, Mhs $1=0+0+0+0+0+0+0+0$ $=0$

Mhs 1 , Mhs $4=0+0+0+0+0+0+1+1$ $=0,25$
Mhs 4 , Mhs $1=0+0+0+0+0+0+0+0$ $=0$

Mhs 1 , Mhs $5=0+0+0+0+1+1+1+1$ $=0,5$

Mhs 5 , Mhs $1=1+0+1+0+0+0+0+0$ $=0,25$

Mhs 1 , Mhs $6=0+0+0+1+0+0+0+1$ $=0,25$

Mhs 6, Mhs $1=0+0+0+0+0+0+0+0$ $=0$ 
Mhs 2 , Mhs $3=1+1+1+1+1+0+1+1$

$$
=0,875
$$

Mhs 3, Mhs $2=0+0+0+0+0+0+0+0$ $=0$

Mhs 2, Mhs $4=0+0+1+0+0+0+1+0$

$$
=0,25
$$

Mhs 4 , Mhs $2=0+0+0+1+1+0+0+0$

$$
=0,25
$$

Mhs 2, Mhs $5=0+0+0+0+0+1+0+0$

$$
=0,125
$$

Mhs 5, Mhs $2=1+0+0+1+0+0+1+0$

$$
=0,375
$$

Mhs 2 , Mhs $6=0+0+1+0+0+0+0+0$

$$
=0,125
$$

Mhs 6, Mhs $2=0+0+0+0+1+0+0+0$

$$
=0,125
$$

Mhs 3, Mhs $4=0+0+0+0+0+0+0+0$

$$
=0
$$

Mhs 4 , Mhs $3=1+1+1+1+1+0+0+1$ $=0,75$
Mhs 3, Mhs $5=0+0+0+0+0+1+0+0$

$$
=0,125
$$

Mhs 5 , Mhs $3=1+1+1+1+1+0+0+1$

$$
=0,75
$$

Mhs 3, Mhs $6=0+0+0+0+0+0+0+0$

$$
=0
$$

Mhs 6, Mhs $3=1+1+1+0+1+0+1+1$

$$
=0,75
$$

Mhs 4 , Mhs $5=0+0+0+0+1+1+0+0$

$$
=0,25
$$

Mhs 5, Mhs $4=1+0+1+0+0+0+0+0$

$$
=0,25
$$

Mhs 4 , Mhs $6=0+0+0+1+0+0+0+0$

$$
=0,125
$$

Mhs 6, Mhs $4=0+0+0+0+0+0+1+0$

$$
=0,125
$$

Mhs 5, Mhs $6=1+0+1+1+0+0+0+0$

$$
=0,375
$$

Mhs 6, Mhs $5=0+0+0+0+1+1+1+0$

$$
=0,375
$$

Setelah perhitungan pada indeks preferensi multikriteria, hasil dan perhitungan tersebut disusun dalam tabel guna mempermudah dalam perhitungan pada proses selanjutnya.

Tabel 5. Arah Preferensi

\begin{tabular}{|c|c|c|c|c|c|c|c|}
\hline Alternatif & Mhs 1 & Mhs 2 & Mhs 3 & Mhs 4 & Mhs 5 & Mhs 6 & $\boldsymbol{\Sigma}$ \\
\hline Mhs 1 & - & 0,375 & 0,875 & 0,25 & 0,5 & 0,25 & 2,25 \\
\hline Mhs 2 & 0,125 & - & 0,875 & 0,25 & 0,125 & 0,125 & 1,5 \\
\hline Mhs 3 & 0 & 0 & - & 0 & 0,125 & 0 & 0,125 \\
\hline Mhs 4 & 0 & 0,25 & 0,75 & - & 0,25 & 0,125 & 1,375 \\
\hline Mhs 5 & 0,25 & 0,375 & 0,75 & 0,25 & - & 0,375 & 2 \\
\hline Mhs 6 & 0 & 0,125 & 0,75 & 0,125 & 0,375 & - & 1,375 \\
\hline$\sum$ & 0,375 & 1,125 & 4 & 0,875 & 1,375 & 0,875 & - \\
\hline
\end{tabular}

c. Menghitung arah preferensi berdasarkan nilai indeks leaving flow, entering flow dan net flow.

Selanjutnya masuk kedalam tahap perhitungan nilai indeks leaving flow, entering flow, dan net flow berdasarkan hasil indeks preferensi.

\section{Leaving Flow}

Mhs $1=2,25 * 1 /(8-1)=2,25 * 1 / 7=0,321$

Mhs $2=1,5 * 1 /(8-1)=1,5 * 1 / 7=0,232$

Mhs $3=0,125 * 1 /(8-1)=0,125 * 1 / 7=0,214$

Mhs $4=1,375 * 1 /(8-1)=1,375 * 1 / 7=0,196$

Mhs $5=2 * 1 /(8-1)=2 * 1 / 7=0,286$

Mhs $6=1,375 * 1 /(8-1)=1,375 * 1 / 7=0,214$ 


\section{Entering Flow}

Mhs $1=0,375 *(8-1)=0,375 / 7=0,321$

Mhs $2=1,125 *(8-1)=1,125 / 7=0,232$

Mhs $3=4 *(8-1)=4 / 7=0,018$

Mhs $4=0,875 *(8-1)=0,875 * 7=0,196$

Mhs $5=1,375 *(8-1)=1,375 * 7=0,268$

Mhs $6=0,875 *(8-1)=0,875 * 7=0,214$

\section{Net Flow}

Mhs $1=0,321-0,054=0,268$

Mhs $2=0,232-0,143=0,089$

Mhs $3=0,214-0,125=-0,571$

Mhs $4=0,196-0,125=0,071$

Mhs $5=0,268-0,214=0,054$

Mhs $6=0,018-0,589=0,089$

Tabel 6. Nilai Leaving Flow, Entering Flow dan Net Flow

\begin{tabular}{|c|c|c|c|c|}
\hline No & Alternatif & Leaving Flow & Entering Flow & Net Flow \\
\hline 1 & Mhs 1 & 0,321 & 0,054 & 0,268 \\
\hline 2 & Mhs 2 & 0,232 & 0,143 & 0,089 \\
\hline 3 & Mhs 3 & 0,018 & 0,589 & $-0,571$ \\
\hline 4 & Mhs 4 & 0,196 & 0,125 & 0,071 \\
\hline 5 & Mhs 5 & 0,268 & 0,214 & 0,054 \\
\hline 6 & Mhs 6 & 0,214 & 0,125 & 0,089 \\
\hline
\end{tabular}

d. Perangkingan

Setelah diperoleh nilai leaving flow, entering flow, dan net flow. Selanjutnya masuk kedalam tahap perangkingan dimana rangking di tentukan berdasarkan nilai net flow. Berikut adalah hasil perangkingan dari setiap alternatif:

Tabel 7. Perangkingan

\begin{tabular}{|c|c|c|c|}
\hline No & Alternatif & Net Flow & Ranking \\
\hline 1 & Mhs 1 & 0,268 & 1 \\
\hline 2 & Mhs 2 & 0,089 & 2 \\
\hline 3 & Mhs 3 & $-0,571$ & 6 \\
\hline 4 & Mhs 4 & 0,071 & 4 \\
\hline 5 & Mhs 5 & 0,054 & 5 \\
\hline 6 & Mhs 6 & 0,089 & 3 \\
\hline
\end{tabular}

Berdasarkan tabel 7. dapat dilihat bahwa yang memperoleh nilai tertinggi adalah alternatif Mhs 1 dengan nilai net flow 0,268. Maka alternatif Mhs 1 yang menjadi proposal terbaik dalam pemilihan seleksi proposal program kreativitas mahasiswa (PKM).

\section{KESIMPULAN}

Dari hasil perhitungan dengan menggunakan algoritma promethee dalam penentuan seleksi proposal program kretivitas mahasiswa (PKM) maka alternatif 
yang lulus seleksi berkas sesuai dengan urutan tertinggi sampai terendah yaitu alternatif Mhs 1 dengan nilai net flow 0,268 alternatif Mhs 2 dengan nilai net flow 0,089 alternatif Mhs 6 dengan nilai net flow 0,089 alternatif Mhs 4 dengan nilai net flow 0,071 dan alternatif Mhs 5 dengan nilai net flow 0,054 dan alternatif terendah yaitu Mhs 3 dengan nilai net flow -0,571. Maka dengan itu, dapat disimpulkan bahwa algoritma promethee dapat diterapkan pada aplikasi berbasis web dimana dari hasil perhitungan tersebut didapat kesamaan nilai antara sistem dan perhitungan menggunakan algoritma promethee. Dari hasil perhitungan tersebut dapat menjadi rekomendasi kepada LPPM dalam menentukan seleksi berkas proposal program kretivitas mahasiswa (PKM).

\section{DAFTAR PUSTAKA}

[1] S. Sundari et al., "Sistem Pendukung Keputusan Dengan Menggunakan Metode Electre Dalam Merekomendasikan Dosen Berprestasi Bidang Ilmu Komputer ( Study Kasus di AMIK \& STIKOM Tunas Bangsa )," no. x, 2012.

[2] H. Rohayani and T. Informatika, "Analisis Sistem Pendukung Keputusan Dalam Memilih Program Studi Menggunakan Metode Logika Fuzzy," vol. 5, no. 1, pp. 530-539, 2013.

[3] A. Wanto and A. P. Windarto, "Analisis Prediksi Indeks Harga Konsumen Berdasarkan Kelompok Kesehatan Dengan Menggunakan Metode Backpropagation," J. Penelit. Tek. Inform., vol. 2, no. 2, pp. 37-44, 2017.

[4] E. Setyaningsih, "PEMILIHAN ALTERNATIF EFISIENSI ENERGI MENGGUNAKAN METODE MCDM-PROMETHEE (Studi Kasus : UKM Batik Supriyarso Kampung Batik Laweyan)," 2017.

[5] S. Rahmawati, "Proses Seleksi Karyawan Baru Bagian Sales Pada PT Mitra Sukses Karya Bersama Bekasi," vol. 5, no. 1, pp. 99-106, 2017.

[6] Santoso and W. Yuliyanti, "Perencanaan Dan Pembuatan Aplikasi Absensi Dosen Menggunakan Radio Frequency Identification ( RFID ) ( Studi Kasus Politeknik Negeri Tanah Laut )," Semin. Nas. Inov. DAN Apl. Teknol. DI Ind., pp. 332-337, 2016. 